\title{
Active and passive vertical motion of zooplankton in a lake
}

\author{
Andrea M. R. Huber, ${ }^{\mathrm{a}, \mathrm{b},{ }^{*}}$ Frank Peeters, ${ }^{\mathrm{a}}$ and Andreas Lorkeb \\ a Limnological Institute, University of Konstanz, Konstanz, Germany \\ b Institute for Environmental Sciences, University Koblenz-Landau, Landau, Germany
}

\begin{abstract}
Temporal variability of vertical zooplankton distributions is analyzed on timescales from minutes to days based on 7 months of acoustic backscatter strength data in Lake Constance. A comparison with net samples reveals that most of the observed variability in volume backscatter strength is associated with variations in the abundance of large Daphnia. Diel vertical migration (DVM) of zooplankton was a persistent feature throughout the entire period of observation, while amplitude, daily migration timing, and migration speed varied with season. This active motion of zooplankton was affected by internal waves on a broad range of timescales. In spring, the maximum depth of DVM follows variations in isothermal depths associated with long-wavelength, basin-scale internal waves. Propagating, short-wavelength, internal waves with comparable amplitudes affect vertical zooplankton distributions on timescales of minutes. Spectral analyses of zooplankton abundance, temperature, and current velocity reveal close correspondence of spectral peaks and slopes, indicating that up to timescales of several days, the only temporal scale at which biological processes dominate over passive transport is associated with DVM. Whereas horizontal transport dominates at long periods, vertical transport occurs only at short timescales.
\end{abstract}

By definition, plankton organisms are passively advected and spatially distributed by current velocities exceeding their own swimming capabilities. Following this definition, spatial and temporal variability of plankton distribution is either generated by currents or is restricted to scales at which variability of plankton abundance is determined by differential growth and mortality (Folt and Burns 1999; Pinel-Alloul and Ghadouani 2007). In lakes, the latter scales are in the horizontal dimensions associated with variations of depth (e.g., littoral-pelagic gradients) and hence with basin scales. For zooplankton in lakes, which is most abundant in size classes around and smaller than one millimeter, the swimming speed can be estimated to be within a few body lengths per second (Huntley and Zhou 2004). Hence, in horizontal dimensions, with typical current velocities of several centimeters per second (Wüest and Lorke 2003), zooplankton meet the criteria of passive plankton organisms. While wind and surface waves provide the major driving force in the epilimnion, major horizontal currents within the meta- and hypolimnion of stratified lakes are mainly associated with internal waves (Wüest and Lorke 2003). Most of the internal wave energy can be found in standing basin-scale waves (internal seiches), which have periods between hours and days, depending on the size of the respective basin and strength of vertical density stratification (Antenucci et al. 2000; Boehrer et al. 2000). Such long waves are shallow-water waves with mainly horizontal wave-induced current velocities, and the resulting passive transport of zooplankton is described by Rinke et al. (2007, 2009). In the vertical dimension, however, current velocities are restricted by gravity to fluctuations with zero mean displacement, and zooplankton are well-known for being able to perform purposive movements over long distances, e.g., by performing a diel

\footnotetext{
*Corresponding author: andrea.huber@uni-konstanz.de
}

vertical migration (DVM) (Stich and Lampert 1981; Ringelberg 1999; Cohen and Forward 2009). Vertical velocity fluctuations are caused by turbulence and shortwavelength, propagating internal waves. The associated scales of vertical displacement in turbulent eddies are restricted to the depth of the upper mixed layer and the buoyancy length scale (Ozmidov scale) within the stratified part of the water column, respectively (Lorke and Wüest 2002). Increased sampling resolution in recent years, however, has revealed the ubiquitous existence of shortwavelength and propagating internal waves in stratified parts of the water column (Imberger 1998; Boegman et al. 2003; Lorke et al. 2006). Such waves are typically observed near the upper-frequency limit for wave propagation determined by stratification and have corresponding periods in the range of a few minutes at the depth of the thermocline. Their amplitudes can exceed $10 \mathrm{~m}$, and the associated vertical velocities are in the range of centimeters per second, thus exceeding zooplankton swimming velocities by one order of magnitude. During daytime, the resulting vertical displacement of zooplankton also causes changes in ambient light intensity and therefore exposure to visual predation. Relative changes in light intensity at comparable timescales are known to be a stimulus for vertical migration (Ringelberg 1999). Passive displacement by internal wave motion and adjustment of their vertical position by directed swimming can be expected to result in complex and dynamic patterns in vertical distributions of zooplankton in their natural environment.

Investigations of the interaction between active and passive vertical transport of zooplankton require observation techniques exceeding the capabilities of traditional net sampling (Holliday et al. 2003; Pinel-Alloul and Ghadouani 2007). Acoustic measurements are widely used for the observation of zooplankton distributions in lakes and oceans. The high spatial and temporal resolution offered by 
this method, combined with the possibility for autonomous deployment or ship-based operation, can be used for longterm measurements of DVM (Pinot and Jansá 2001; Cottier et al. 2006; Record and de Young 2006) and spatial distribution of zooplankton (Greene et al. 1998; Hembre and Megard 2003), respectively. Such high-resolution data allow the spectral distribution of zooplankton variability to be determined and thus provide a direct comparison to spectral characteristics obtained from theoretical arguments or numerical models (Abraham 1998; Lovejoy et al. 2001). Differences observed in the spectral characteristics of plankton distributions and current velocities, or of passive scalars like temperature, have been used to differentiate between physical and biological processes generating variability at the corresponding spatial and temporal scales (Mackas et al. 1985; Powell and Okubo 1994). Knowledge of the spectral characteristics of plankton variability allows us to further analyze trophic interactions occurring in the patchy distributions (Martin and Srokosz 2002; Bracco et al. 2009).

In this study, we tested the hypotheses (1) that vertical distributions of zooplankton in lakes are influenced by internal wave motions on timescales ranging from minutes to days, and (2) that changes in light intensity due to vertical displacement by propagating, short-wavelength internal waves, in particular, provide frequent triggers for active vertical migration of zooplankton. We analyzed long-term and high-resolution observations of vertical profiles of zooplankton abundance estimated from acoustic backscatter strength. Simultaneous observations of vertical profiles of temperature and current velocity were used to identify timescales of active and passive vertical displacement and to characterize the spectral distribution of variance.

\section{Methods}

Study site-Lake Constance (Bodensee) is a large, monomictic, prealpine lake situated at the northern edge of the European Alps on the borders of Germany, Switzerland, and Austria (Fig. 1). With a surface area of $473 \mathrm{~km}^{2}$, an average depth of $100 \mathrm{~m}$, and a maximum depth of $254 \mathrm{~m}$, Lake Constance is among the largest and deepest lakes in Europe. Our sampling station was situated near the center of Lake Überlingen (Überlinger See), a side basin of Lake Constance (Fig. 1) having a maximum depth of $140 \mathrm{~m}$. Detailed descriptions of the lake's morphology, hydrology, and hydrodynamics can be found in Bäuerle et al. (1998).

The lake suffered from eutrophication between 1960 and 1980 and since then has undergone intensive reoligotrophication. Since the 1990s, the lake has returned almost to its natural state and is classified as oligotrophic (Güde et al. 1998). Along with its trophic state, the composition of the zooplankton community in Lake Constance has changed dramatically over the past decades (Straile and Geller 1998). At present, the crustacean zooplankton biomass consists mainly of cyclopoid copepods (Cyclops sp. and Mesocyclops leuckarti) and two Daphnia species (Daphnia galeta and Daphnia hyalina), as well as smaller fractions of

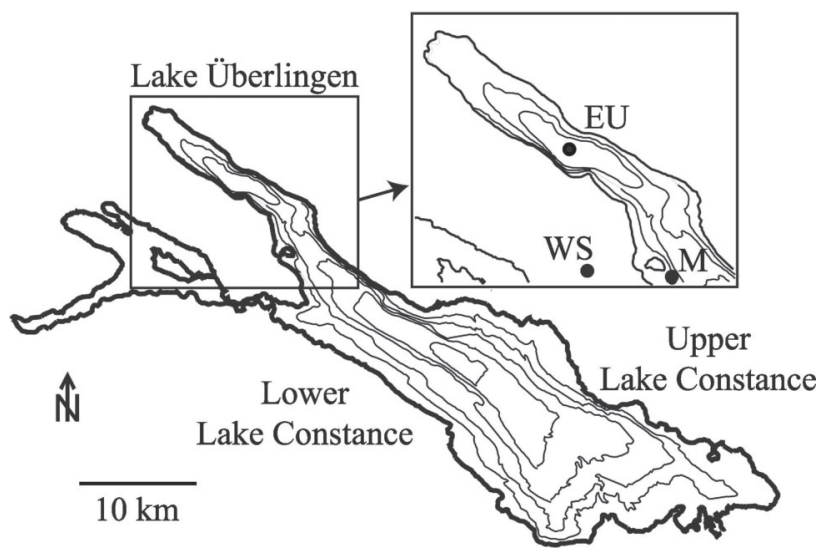

Fig. 1. Map of Lake Constance $\left(47^{\circ} 83^{\prime} 99^{\prime \prime} \mathrm{N}, 9^{\circ} 81^{\prime} 89^{\prime \prime} \mathrm{E}\right)$ and the sampling stations. Contour lines represent isobaths in $50-\mathrm{m}$ increments. EU marks the location of the long-term acoustic observations in Lake Überlingen. The high-resolution data including current velocity were measured at position $\mathbf{M}$, and meteorological data were measured at WS.

the calanoid copepod Eudiaptomus gracilis, Bosmina sp., two macrozooplankton species (Leptodora kindtii and Bythotrephes longimanus) (Geller 1986; Straile and Geller 1998), and very few individuals of the re-emerged cladocera Diaphanosoma brachyurum (Stich et al. 2005).

Hydroacoustic measurements-For stationary long-term observation of acoustic backscatter strength at $500 \mathrm{kHz}$, an acoustic Doppler profiler (ADP; Nortek AS, www. nortek-as.com) was attached downward-looking to a permanent data buoy in Lake Constance (EU, Fig. 1). The instrument had three acoustic transducers (diameter $14 \mathrm{~cm}$ ) pointing in different directions at an angle of $25^{\circ}$ to the vertical axis. It recorded the acoustic echo intensity received from 64 depth cells along the three acoustic beams. Although the major intention of ADPs is to measure vertical profiles of the three-dimensional current velocity by evaluating the Doppler frequency shift between submitted and received acoustic pings, wave-induced motions of the data buoy did not allow for a meaningful analysis of velocity data during this deployment, and our analysis is therefore restricted to the recorded echo intensity.

From 25 April to 28 November 2006, the ADP was deployed at a depth of $1.76 \mathrm{~m}$ and sampled the acoustic echo intensity between $2.76-\mathrm{m}$ and $66.76-\mathrm{m}$ depth with a vertical resolution of $1 \mathrm{~m}$. The measurement frequency was $1 \mathrm{~Hz}$, and three consecutive measurements were internally averaged prior to recording a measurement. For all subsequent analyses, except for the spectral analysis of the original high-frequency data, the measured intensity data were averaged over 5-min time intervals. The maximum profiling range of the instrument was determined for each profile by considering only data with a signal-tonoise ratio exceeding unity, whereas the average noise level was determined as the constant, i.e., depth-independent, value of the echo intensity received from remote profile sections. The resulting maximum profiling range varied between 51.76 and $66.76 \mathrm{~m}$ throughout the measurements. 
Recorder malfunctions and power-supply problems resulted in major data gaps within the deployment period. Volume backscattering strength $(S)$ was estimated from acoustic echo intensity recorded for each depth cell following the procedure described in Lorke et al. (2004, 2008).

Zooplankton abundance-Parallel to the acoustic measurements, zooplankton sampling surveys were conducted 15 times, at least once a month, between April and September 2006. Samples were collected between 0- and 60-m depth within 2.5- to 10-m-long depth intervals. Occasionally, parallel sampling and tows over the entire water column were accomplished, and additional samples were collected in the surface layer, above the actual ADP profiling range. In total, 99 samples were taken over the entire measuring period.

Sampling was performed during daytime between 09:20 $\mathrm{h}$ and 16:15 h Central European Time (CET). All samples were taken in Lake Überlingen, at Sta. EU (Fig. 1), using a closing net (Apstein-plankton net, opening diameter $17 \mathrm{~cm}$, mesh size $100 \mu \mathrm{m}$, Hydrobios, http://www.hydrobios.de). Towing speed of the net was approximately $0.5 \mathrm{~m} \mathrm{~s}^{-1}$. Zooplankton specimens were fixed in $4 \%$ sucrose-formaldehyde-solution for later taxon- and size-specific counting under a dissecting microscope. Zooplankton abundance was estimated for the following groups: macrozooplankton, Bosmina sp., and two size groups ( $<1$ and $>1 \mathrm{~mm}$ ) of Daphnia sp. and copepods (Cyclops sp. and Eudiaptomus gracilis), respectively. Samples with high numbers of individuals were separated by using the Geller subsampler (Schwoerbel 1966).

Temperature stratification and meteorological parameters-Vertical temperature stratification was measured using thermistor chains deployed at the same data buoy as the ADP. From 26 April to 14 June 2006, a thermistor chain consisting of 34 thermistors (Precision Measurement Engineering, http://www.pme.com) between 0.1- and 135-m depth was deployed using a sampling interval of $1 \mathrm{~min}$. From 0.1 - to $3.5-\mathrm{m}$ depth, thermistors were spaced at 20- to $50-\mathrm{cm}$ intervals, from 4 to $20 \mathrm{~m}$ by 1 - to $2-\mathrm{m}$ intervals and below $20 \mathrm{~m}$ by 5 - to $10-\mathrm{m}$ intervals. Due to breakdown of the thermistor chain, measurements were continued with 13 RBR (RBR-TR-1050, http://www.rbr-global.com) and Vemco (http://www.vemco.com) thermistors measuring temperature every $10 \mathrm{~s}$ (RBR) and every $10 \mathrm{~min}$ (Vemco) between 26 August and 28 November 2006. The uppermost two thermistors were located at $0.1-$ and $6-\mathrm{m}$ water depth, and further loggers followed in 4-m steps until $30 \mathrm{~m}, 5 \mathrm{~m}$ steps until $40 \mathrm{~m}$, and $10 \mathrm{~m}$ steps until $70 \mathrm{~m}$. For all subsequent analysis, except the spectral analysis of highfrequency data, the thermistor data of the second measuring period were averaged within 10-min intervals (sampling period of the Vemco thermistors).

Short-wavelength solar radiation and other meteorological data were measured on top of the data buoy (EU) until 26 August 2006 at 1-min resolution. Additional data for solar radiation, measured at a meteorological station in the city of Constance (WS, Fig. 1), were provided by the
German Meteorological Service (Deutscher Wetterdienst) with a temporal resolution of $1 \mathrm{~h}$.

High-resolution measurements-An additional mooring, consisting of an upward-looking $600-\mathrm{kHz}$ Acoustic Doppler Current Profiler (ADCP, $600 \mathrm{kHz}$ workhorse [model RDI-WH600 Sentinel], Teledyne RD Instruments, http:// www.rdinstruments.com) at 19-m depth, and 9 RBR temperature loggers between 19- and 11-m depth, was deployed from 01 to 04 September 2006 at 50-m water depth near the shore of Lake Constance (M, Fig. 1). The mooring was bottom-mounted and mechanically decoupled from surface wave motion, enabling us to measure the three-dimensional current velocity in combination with acoustic echo intensity within profiling range of the ADCP. The instrument was operated in pulse-coherent mode (RDI mode 5), offering high-resolution velocity measurements $\left( \pm 0.3 \mathrm{~cm} \mathrm{~s}^{-1}\right)$ and small vertical bin sizes $(0.1 \mathrm{~m})$ over a restricted maximum profiling range of $8 \mathrm{~m}$. The thermistors sampled every $30 \mathrm{~s}$. The ADCP measured echo intensity and velocity profiles every second, while internally averaged data were recorded every $3 \mathrm{~s}$.

\section{Results}

Relationship between acoustic backscatter strength and zooplankton abundance-Although measurements of volume backscatter strength cannot distinguish among different species or size groups of zooplankton, which usually differ in abundance as well as in their acoustic properties, such measurements can be related to zooplankton abundance. This can be done either by employing assumptions about the particular target strength of individual (ind.) organisms (Sutor et al. 2005) or empirically (Hembre and Megard 2003). We decided to follow the latter because of the sparse resolution of our net sampling and the differentiation in only two size groups. To analyze the species of zooplankton that contributed to the observed acoustic backscatter strength, we applied two different regression analyses between backscatter strength averaged over depth and time intervals of the corresponding net tows and zooplankton abundance for six different species and size groups. In order to minimize the effect of instrumental noise on this regression analysis, only samples collected above $40-\mathrm{m}$ depth were considered. On the basis of zooplankton abundance sampled between $0-5 \mathrm{~m}$ and 0 $10 \mathrm{~m}$, backscatter strength was extrapolated from the depth of the first measurement $(2.76 \mathrm{~m})$ to the surface by assuming a constant zooplankton concentration within that depth interval. Altogether, 45 zooplankton samples were used for the regressions analysis.

The results of multiple linear regression of acoustic backscatter strength and measured zooplankton abundances in all six functional and size groups are summarized in Table 1 and Fig. 2A. Total $r^{2}$ is 0.56, and the highest significance can be observed for large Daphnia $(p=0.009)$, and macrozooplankton; small Daphnia $(<1 \mathrm{~mm})$, Bosmina, and large and small copepods follow in decreasing order of significance ( $p$ values). It should be noted, that the abundances of macrozooplankton and Bosmina were very 
Table 1. Multiple linear regression and corresponding $p$ values of zooplankton abundance (ind $\mathrm{L}^{-1}$ ) observed in six functional and size groups and acoustic backscatter strength $(\mathrm{dB})$.

\begin{tabular}{lcccccc}
\hline \hline & Bosmina & $\begin{array}{c}\text { Daphnia } \\
(>1 \mathrm{~mm})\end{array}$ & $\begin{array}{c}\text { Daphnia } \\
(<1 \mathrm{~mm})\end{array}$ & $\begin{array}{c}\text { Copepoda } \\
(>1 \mathrm{~mm})\end{array}$ & $\begin{array}{c}\text { Copepoda } \\
(<1 \mathrm{~mm})\end{array}$ & $\begin{array}{c}\text { Macrozoo- } \\
\text { plankton }\end{array}$ \\
\hline Slope $\left(\mathrm{dB}^{-1}\right.$ ind $\left.\mathrm{L}^{-1}\right)$ & 12.9 & 2.31 & -3.92 & 2.70 & -0.154 & 52.0 \\
$p$ & 0.026 & 0.0092 & 0.029 & 0.077 & 0.54 & 0.021 \\
\hline
\end{tabular}

Intercept: $-116.7 \pm 1.5 \mathrm{~dB}, r^{2}=0.56$.

low $(<5 \%)$ throughout all measurements. The regression coefficients for small Daphnia and small Copepoda are negative, indicating that these variables and their corresponding $p$ values are without any realistic significance. The unexpected negative coefficients, indicating decreasing backscatter strength with increasing abundance of the respective zooplankton group, can be attributed to the inevitable covariation and statistical dependence of the six groups and the limited number of samples. The obtained regression coefficients vary between values of $\approx 2 \mathrm{~dB}$ ind $^{-1}$ L (large Daphnia) and $>50 \mathrm{~dB}$ ind $^{-1} \mathrm{~L}$ (macrozooplankton). The magnitudes of these coefficients are, among many other acoustical properties of the corresponding scatterers, related to zooplankton size (acoustic cross-sectional area).

A more mechanistic approach, however, requires taking the logarithmic scale of $S$ into account. The observed volume backscattering strength $S$ is related to the abundance $A_{i}$ and acoustic cross-sectional area $\sigma_{i}$ of the respective group $i$ of scatterers by:

$$
S=C+10 \log _{10}\left(\sum_{i} A_{i} \sigma_{i}\right)
$$

where $C$ is an unknown constant resulting from a lack of calibration of the ADP in terms of absolute values of $S$.
Hence, a multiple linear regression of

$$
10^{S / 10}=C^{\prime} \sum_{i} A_{i} \sigma_{i}
$$

with zooplankton abundance $A_{i}$ observed in group $i$ as an independent variable, provides regression coefficients that are related to the acoustic cross-sectional area of the respective zooplankton group. Application of stepwise linear regression to Eq. 2 (Table 2) reveals that the most significant contribution comes from large Daphnia $(p<3$ $\left.\times 10^{-9}\right)$. The next most significant group is small Daphnia $(p<0.01)$; however, this group has a negative regression coefficient. The remaining zooplankton groups have similar, very poor statistical significance $(p>0.1)$. Taking into account the unrealistic sign of the regression coefficient for small Daphnia $(<1 \mathrm{~mm})$, which can be attributed to statistical interdependence of the groups, and because the overall root mean square error of the total regression is reduced by only $12 \%$ upon inclusion of small Daphnia, it can be concluded that the variability of volume backscattering strength can be predominantly described by the abundance of large Daphnia $(>1 \mathrm{~mm})$. This result is in accordance with observations of Hembre and Megard (2003) in a Minnesota lake. The reasons for the strong acoustic backscatter from Daphnia, in comparison to more
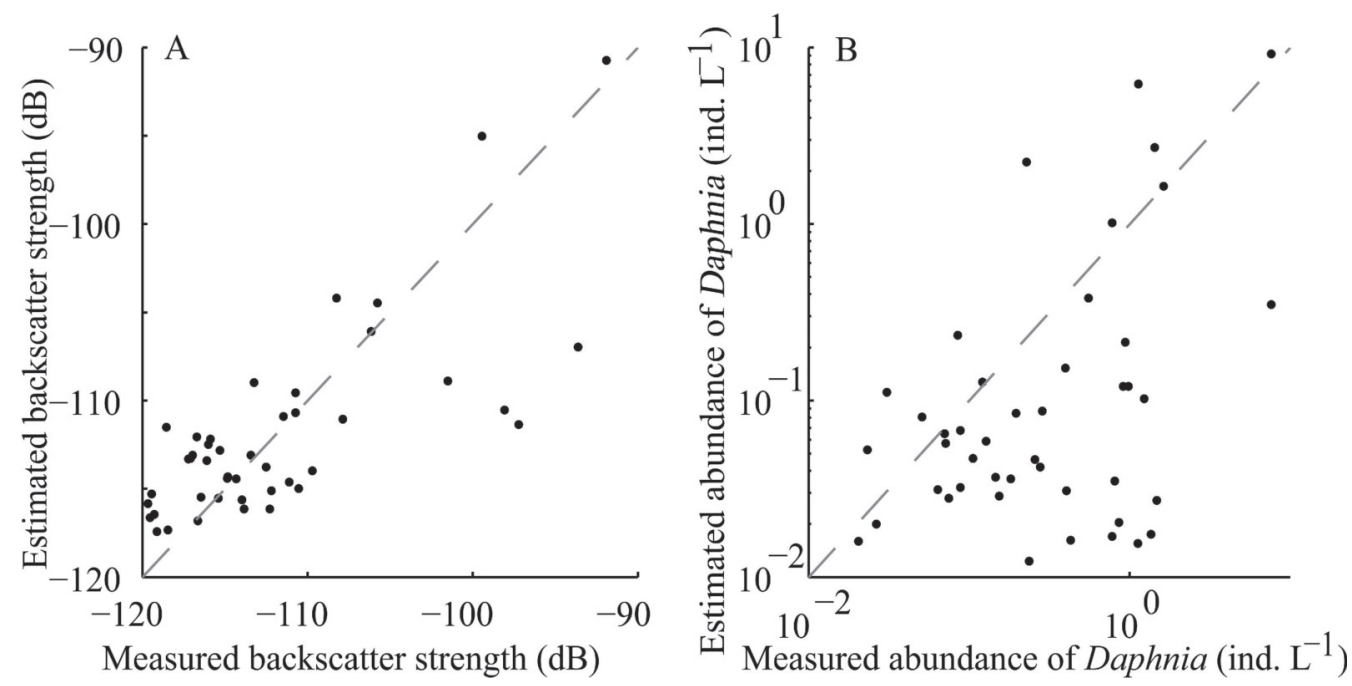

Fig. 2. Correlation between volume backscatter strength and sampled zooplankton abundance. (A) Volume backscatter strength $S$ and its equivalent obtained by multiple linear regression with the measured abundances in all functional and size groups (Table 1). The dashed line marks is the 1:1 relationship. (B) Relation between Daphnia abundance estimated from acoustic backscatter strength using Eq. 3 and measured Daphnia abundance (ind $\mathrm{L}^{-1}$ ). 
Table 2. Stepwise linear regression of zooplankton abundance (ind $\mathrm{L}^{-1}$ ) observed in six functional and size groups and linearized acoustic backscatter strength $\left(10^{S / 10}\right)$ according to Eq. 3. The corresponding $p$ values and standard errors of the coefficients are indicated.

\begin{tabular}{lcccccc}
\hline \hline & Bosmina & $\begin{array}{c}\text { Daphnia* } \\
(>1 \mathrm{~mm})\end{array}$ & $\begin{array}{c}\text { Daphnia } \\
(<1 \mathrm{~mm})\end{array}$ & $\begin{array}{c}\text { Copepoda } \\
(>1 \mathrm{~mm})\end{array}$ & $\begin{array}{c}\text { Copepoda } \\
(<1 \mathrm{~mm})\end{array}$ & Macrozooplankton \\
\hline Coefficient (ind $\left.\mathrm{L}^{-1}\right)$ & $7.9 \times 10^{-11}$ & $6.8 \times 10^{-11}$ & $-6.8 \times 10^{-11}$ & $-6.2 \times 10^{-12}$ & $1.1 \times 10^{-12}$ & $2.2 \times 10^{-10}$ \\
$p$ & 0.3 & $5 \times 10^{-8}$ & $8 \times 10^{-3}$ & 0.7 & 0.7 & 0.4 \\
SE & $8 \times 10^{-11}$ & $1 \times 10^{-11}$ & $2 \times 10^{-11}$ & $2 \times 10^{-11}$ & $3 \times 10^{-12}$ & $3 \times 10^{-10}$ \\
\hline
\end{tabular}

* Intercept and $r^{2}$ for a regression with abundance of large $(>1 \mathrm{~mm})$ Daphnia as the only significant regression variable are $5.2 \times 10^{-12}$ ind $\mathrm{L}^{-1}$ and 0.50 , respectively.

abundant but smaller zooplankton organisms, is their optimum size for the chosen acoustic wavelength (backscatter strength at $500 \mathrm{kHz}$ is maximal from particles having an equivalent spherical diameter of about $1 \mathrm{~mm}$ ) and, most probably, also the presence of a two-limbed chitin carapax with a corresponding strong density and sound speed contrast.

The corresponding regression can be inverted to estimate an equivalent of Daphnia abundance $(A)$ from volume backscatter strength $S$ :

$$
A=\frac{1}{c_{\text {Daph }}} 10^{S / 10}
$$

where $c_{\text {Daph }}=\mathrm{C}^{\prime} \sigma=(7 \pm 1) \times 10^{-11}$ ind $^{-1} \mathrm{~L}$ is the corresponding regression coefficient and associated standard error. The relation between Daphnia abundance estimated from acoustic backscatter strength using Eq. 3 and sampled abundance (ind $\mathrm{L}^{-1}$ ) is shown in Fig. 2B. The obtained single-group regression is (1) invertible, i.e., it can be used to estimate abundance based on acoustic backscatter, (2) based on physically sound assumptions, and (3) free of spurious regression statistics caused by covariation and statistical dependence of multiple abundances and resulting negative regression coefficients. For the following analyses, the observed volume backscatter strength is converted in equivalent Daphnia abundance (ind $\mathrm{L}^{-1}$ ) according to Eq. 3.

Seasonal dynamics of zooplankton and acoustic backscatter-The development of zooplankton abundance during the entire measuring period in 2006 is shown in Fig. 3A. Highest total zooplankton abundance was observed at the beginning of the measurements in May, followed by a strong decrease in the number of individuals in June and a second maximum in July and August. During our observations, the zooplankton community was dominated by copepods (Eudiaptomus and Cyclops), constituting about $78 \%$ (mean value over the whole measuring period) of the total zooplankton abundance in our samples, followed in decreasing order by Daphnia with 17\%, Bosmina (4.5\%), and macrozooplankton (Leptodora and Bythotrephes, $0.5 \%$ ). About $70 \%$ of the zooplankton individuals were smaller than $1 \mathrm{~mm}$, while this group consisted of $88.5 \%$ Copepoda and only $11.5 \%$ Daphnia.

The abundance of Daphnia followed all resolved features of the development of total zooplankton (Fig. 3A). In 2006, Daphnia abundance reached its peak in June, followed by an immediate decrease at the same time as total zooplankton abundance declines, and $62 \%$ of sampled
Daphnia were larger than $1 \mathrm{~mm}$. The equivalent of Daphnia abundance estimated from acoustic backscatter strength (Fig. 3B) roughly follows the seasonal dynamics of Daphnia as estimated from net sampling. Major deviations between both distributions occur, e.g., in spring, when highest values of acoustically estimated Daphnia abundance coincide with the peak in total zooplankton, before the maximum Daphnia abundance was actually sampled.

Diel vertical migration-The acoustic abundance estimates reveal a pronounced diurnal pattern of increased abundances at greater depth during daytime (Fig. 3B,C), which is related to DVM of Daphnia. At the beginning of the measurements in April, DVM had already started. It continued until the end of the measurements at the end of November with varying magnitude, pattern, and daily timing. In spring, DVM was only shallow (above $30-\mathrm{m}$ depth, Fig. 3C), but its amplitude increased slowly over time. During that time of the year, the amplitude of DVM showed strong fluctuations with amplitudes exceeding $20 \mathrm{~m}$. These fluctuations followed the vertical displacement of isotherms, and maximum migration amplitudes were roughly determined by the depth of the $6^{\circ} \mathrm{C}$ isotherm (Fig. 3B,C). Later in the year, the migration amplitude increased until it exceeded the ADPs maximum detectable depth of about $66 \mathrm{~m}$ at the beginning of July. This pattern continued until the end of our measurements at the end of November 2006 (Fig. 3D).

Typical patterns of DVM and their relation to isothermal depths, solar radiation, and the relative rate of change of solar radiation $(s r)$ are exemplified in Fig. 4. Here, $s r$ was estimated from measured values of solar radiation $(I)$ with a resolution of $1 \mathrm{~min}$ :

$$
s r=\frac{d(\ln I)}{d t}=\frac{1}{I} \cdot \frac{d I}{d t}
$$

Ringelberg (1999) described $s r$ is a stimulus for secondary phototaxis if it exceeds a certain threshold value, the rheobase, which the authors estimated for different Daphnia species to be between 0.04 and $0.1 \mathrm{~min}^{-1}$. Our data show that this threshold value was exceeded around daily sunset and sunrise times, but also frequently during daytime on days with partial cloud cover (Fig. 4). The timing of DVM is clearly connected to the seasonal course of sunrise and sunset. Relationships between day-to-day variations in solar radiation caused by cloud cover and the depth and timing of vertical migration could not be observed.

For a statistical analysis of DVM timing and speed, the vertical velocity of migrating zooplankton was estimated 

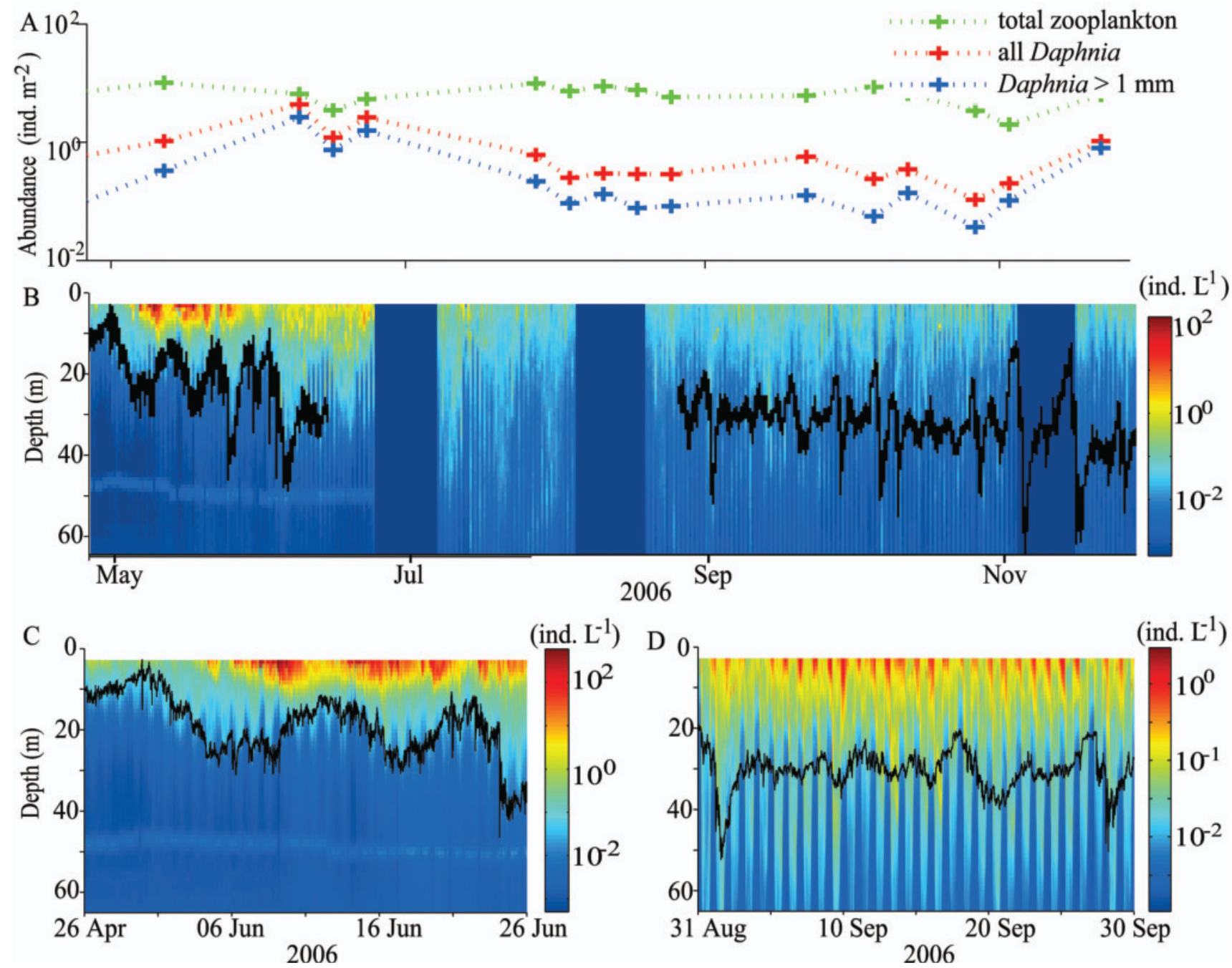

Fig. 3. Sampled and estimated zooplankton abundance at Sta. EU. (A) Vertically integrated abundance of total zooplankton, all Daphnia, and Daphnia $>1 \mathrm{~mm}$ estimated from net sampling. (B) Daphnia abundance estimated from volume backscatter strength for the entire period of observation. Dark-blue blank areas indicate data gaps; black line shows the depth of the $6^{\circ} \mathrm{C}$ isotherm. The light-blue bar around 50-m depth is an artifact of the acoustic measurements. (C, D) Selected time periods of acoustic abundance estimates and isothermal $\left(6^{\circ} \mathrm{C}\right)$ depth during spring and late summer, respectively, at greater detail.

using a one-dimensional velocimetry approach. According to Record and de Young (2006), the vertical velocity of zooplankton $w$ at depth bin $z_{1}$ can be estimated by evaluating the integrated rate of change of abundance above $z_{1}$ (zooplankton must enter or leave the water column at the bottom of bin $z_{1}$ at that rate):

$$
w\left(z_{1}\right)=\frac{\Delta z}{\Delta t} \frac{\sum_{z=z_{1}}^{\text {surface }}\left[S(z)_{n+1}-S(z)_{n}\right]}{S\left(z_{1}\right)}
$$

where $n$ refers to sample index with an associated time step $\Delta t$, and $\Delta z$ is the vertical bin size. The time series of vertical velocity showed two daily peaks associated with upward and downward migration of zooplankton, respectively. The daily time of occurrence and magnitude of these peaks were evaluated at 16.8-m depth (depth bin 14). Whereas the actual time of the day at which the migration occurred depended on the depth chosen for this analysis, the seasonal dynamics of DVM timing closely followed variations in sunset and sunrise (Fig. 5A). Increased scatter of the data at the beginning of the observations in spring are related to less pronounced peaks observed in the migration velocity. Daily variations in the timing of migration are weak from late June until November and, as indicated qualitatively in Fig. 4, are not correlated with day-to-day variations in solar radiation caused by cloud cover. As discussed later herein at greater detail, deviations in the timing of daily migration from the seasonal course of solar radiation are related to vertical advection by internal wave motions.

The speed of upward and downward migration, estimated as the daily maxima and minima of Eq. 5, respectively, varied between 1 and $2 \mathrm{~mm} \mathrm{~s}^{-1}$ (Fig. 5B), 


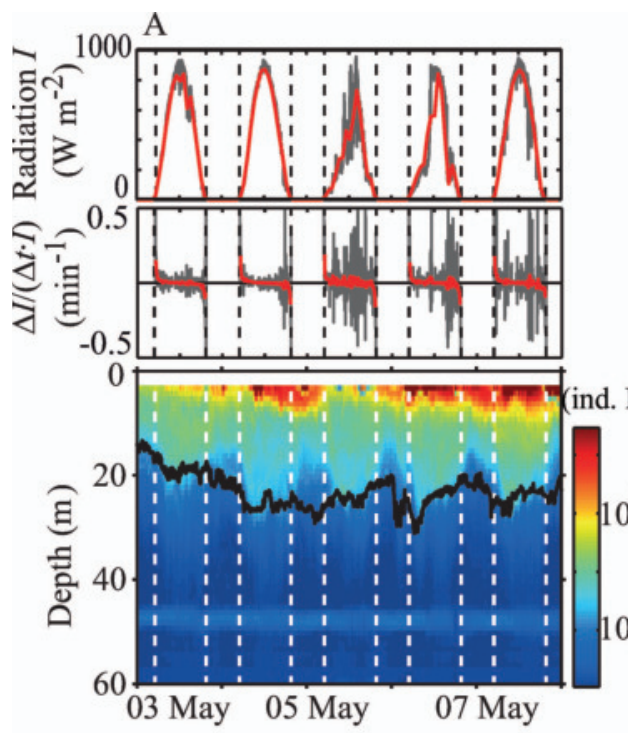

B
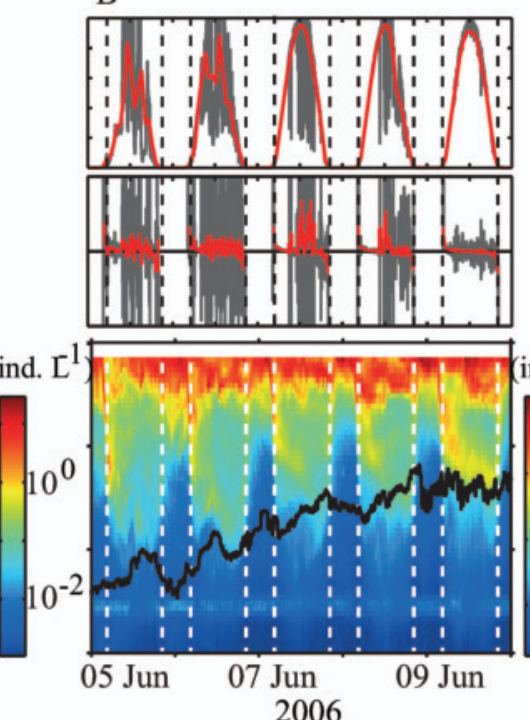

$\mathrm{C}$

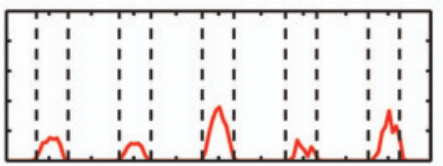

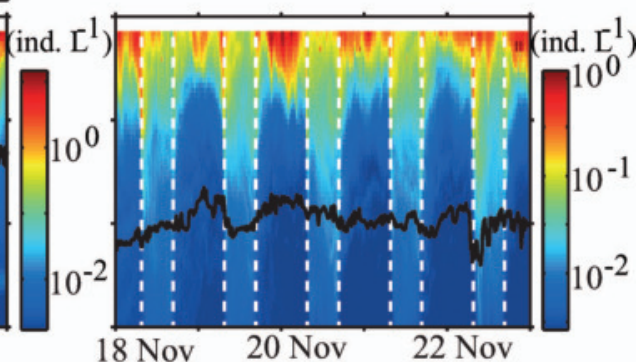

Fig. 4. Solar radiation $I$ (upper panels; gray line: 1-min values, red line: 1-h mean), relative rate of change of solar radiation $s r$ (middle panels; gray line: 1-min values, red line: 30-min running average), and patterns of DVM (lower panels; color coding: logarithmically scaled Daphnia equivalents, black line: depth of the $6^{\circ} \mathrm{C}$ isotherm) during selected time periods in: (A) spring (03-07 May), (B) summer (05-09 June), and (C) winter (18-22 November, no 1-min solar radiation measurements available), respectively. Dashed vertical lines indicate times of sunrise and sunset. (A, B) The light-blue bar at around 50-m depth is an artifact of the acoustic measurements.

while downward migration was significantly faster (total mean: $-1.8 \pm 0.8 \mathrm{~mm} \mathrm{~s}^{-1}$ ) than upward migration (total mean: $1.2 \pm 0.6 \mathrm{~mm} \mathrm{~s}^{-1}$ ). The magnitude of both velocities gradually increased over the observation period and with migration depth. Short-term temporal fluctuations of migration speed were not correlated with cloud cover and are mainly related to internal wave motions.

Passive transport by water movement-Figure 6 shows selected daily patterns of observed vertical distributions of zooplankton and temperature. Whereas Fig. 6A-C exemplifies the rather typical situation where high-frequency internal waves with periods between minutes and hours cause vertical displacements of isotherms and zooplankton with amplitudes exceeding $10 \mathrm{~m}$, Fig. 6D represents a rarely observed quiescent distribution, with constant isothermal depths and undisturbed DVM. In combination with the longer-term distributions shown in Fig. 3B,C, where vertical displacements exceeding $10 \mathrm{~m}$ occur on timescales of 3-4d, the observations suggest that variations of zooplankton abundance are closely related to variations of isothermal depths over a broad range of timescales.

We analyzed the frequency distribution of temperature and zooplankton variance by estimating the power spectral
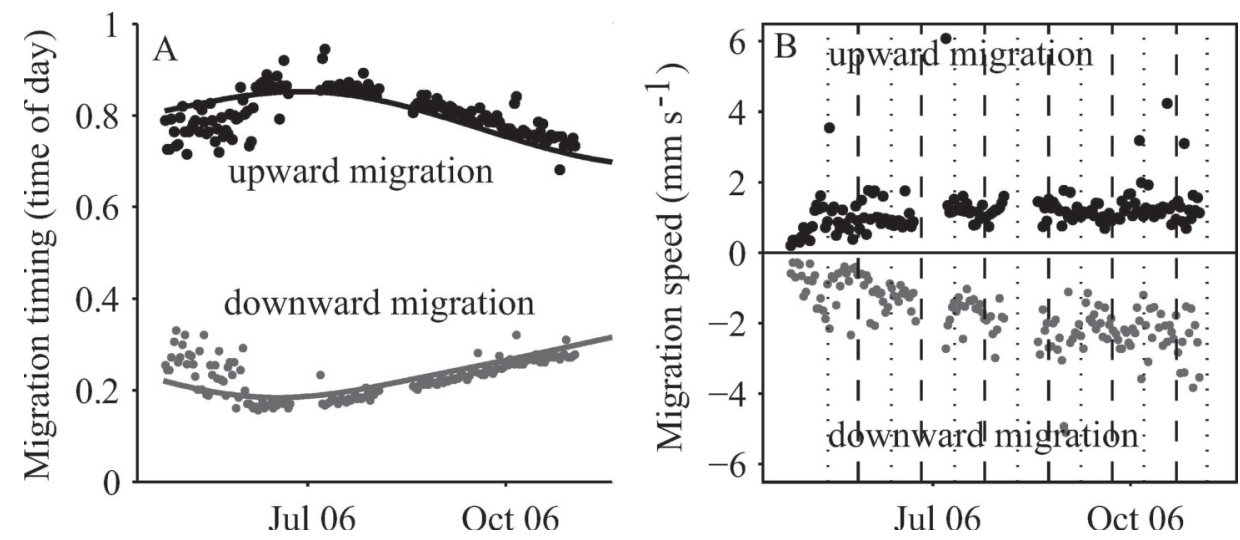

Fig. 5. (A) Timing of downward (gray dots) and upward (black dots) migration of Daphnia at a depth of $16 \mathrm{~m}$ in relation to local sunrise (gray line) and sunset (black line) times. Migration time is scaled as decimal days. (B) Vertical migration speed of Daphnia migrating downward (gray dots, negative speed) and upward (black dots, positive speed). Vertical lines refer to full moon (dotted line) and new moon (dashed line), respectively. 


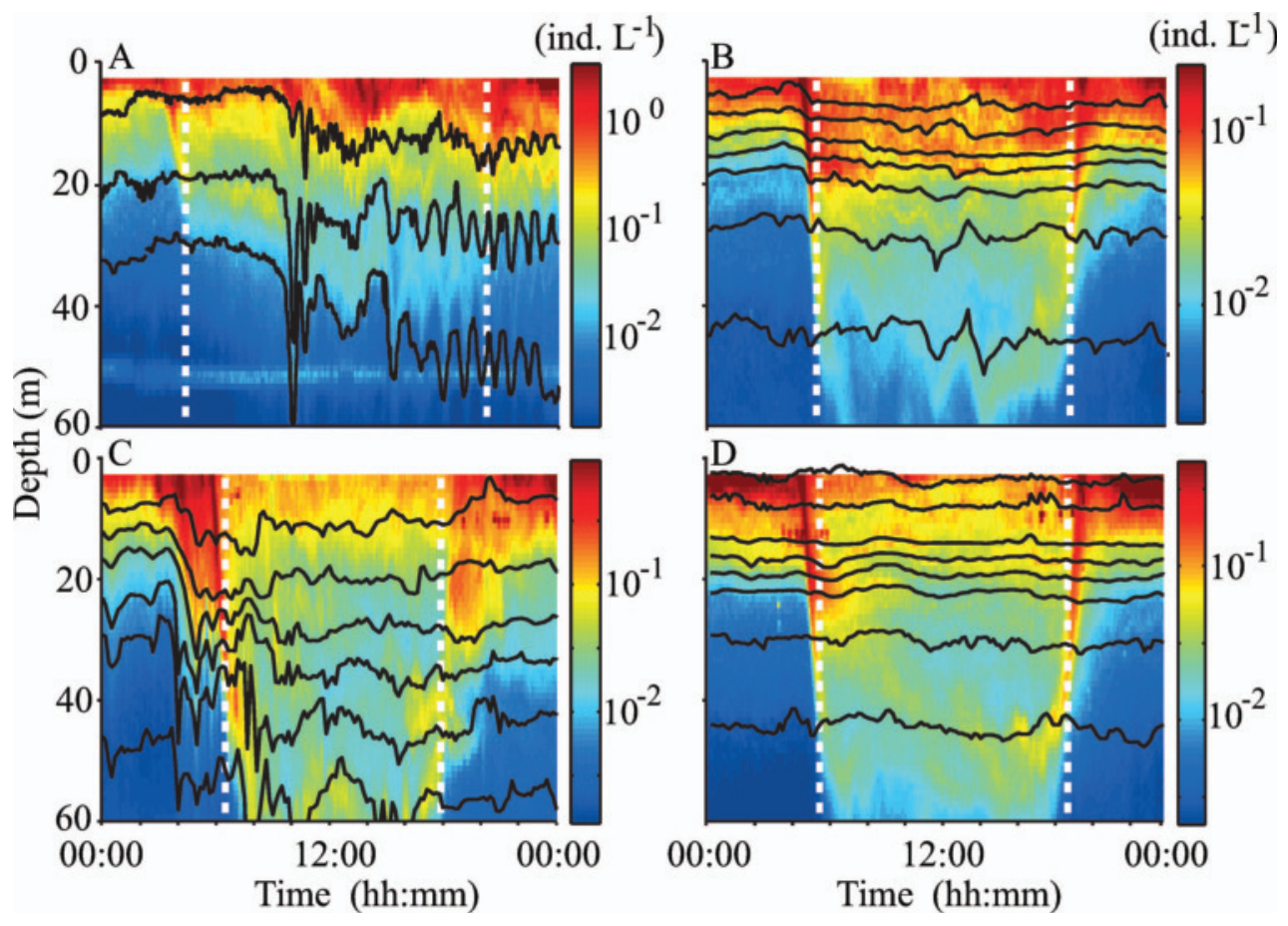

Fig. 6. Diurnal patterns of vertical zooplankton distributions and temperature (black lines are isotherms starting at $6^{\circ} \mathrm{C}$ at $2^{\circ} \mathrm{C}$ increments). White vertical dashed lines indicate local times of sunset and sunrise. (A) 03 June - high-frequency internal wave event in the whole water column, (B) 04 September - internal wave with lower amplitude in deeper water layers, (C) 06 October-passing of an internal front accompanied by high-frequency internal waves, and (D) 06 September - calm conditions in isothermal depths but formation of thin layers.

density of the corresponding time series at 18-m depth (Fig. 7). Within the observed depth range, temperature can be considered as a passive scalar tracer without any sources and sinks, and synchronous fluctuations of temperature and zooplankton abundance can thus be considered to be caused by passive transport. Differences between the variations of both are mainly caused by biological processes, i.e., individual movement or growth and mortality. Both spectra are remarkable similar, and differences are only observed within two frequency ranges. The first difference can be found around a period of $24 \mathrm{~h}$ and its higher harmonics, e.g., at 12 and $6 \mathrm{~h}$, where the zooplankton spectrum reveals distinct peaks that cannot be observed in the temperature spectrum. These peaks in the zooplankton spectrum are related to DVM. Since the observed variability at, e.g., 18-m depth, is not sinusoidal, but rather consists of two daily peaks associated with the passing of migrating plankton, its spectral signature consists of pronounced harmonics of the primary 24-h period. The second difference can be found within the highfrequency part of the spectrum above $\sim 3 \times 10^{-3} \mathrm{~Hz}$ or corresponding periods below $5 \mathrm{~min}$, where the zooplankton spectrum exhibits the properties of white noise, whereas the temperature spectrum further decreases with increasing frequencies. The spectral range where this transition can be observed coincides with a bump in the temperature spectrum marking the high-frequency limit for the occurrence of internal waves. Higher-frequency variance can only be generated by turbulent motions.
High-resolution observations and the occurrence of thin layers of zooplankton-The ADCP and thermistor deployment within the thermocline of Lake Constance, which was mechanically decoupled from surface wave motions, and which employed the high-resolution water profiling mode, enabled us to analyze the observed variability of acoustic backscatter strength not only in relation to temperature, but also in relation to horizontal and vertical current velocities. Combined with the high vertical resolution, these measurements reveal the astonishing temporal dynamics and small-scale vertical structure in all measured quantities within the stably stratified interior of the lake (Fig. 8). The snapshot depicted in the figure shows a metalimnetic jet, a strong horizontal current with speeds exceeding $10 \mathrm{~cm} \mathrm{~s}^{-1}$ confined within a layer of less than 2-m vertical extent (Fig. 8A). A second, but less-pronounced, jet is moving into the opposite direction only $3 \mathrm{~m}$ below this jet. The depths of both are undulated by internal waves with periods between 5 and $10 \mathrm{~min}$ and vertical velocities exceeding $1 \mathrm{~cm} \mathrm{~s}^{-1}$ (Fig. 8B). Both jets are further characterized by a thin, $<1$-m-thick, layer of enhanced acoustic backscatter (Fig. 8C). Although no samples were taken during the high-resolution measurements, these layers could represent layers of zooplankton because, as analyzed previously, zooplankton contribute most of the variance of volume backscatter strength at this range of acoustic frequencies.

Normalized power spectra of horizontal and vertical velocities, temperature, and acoustic backscatter strength 


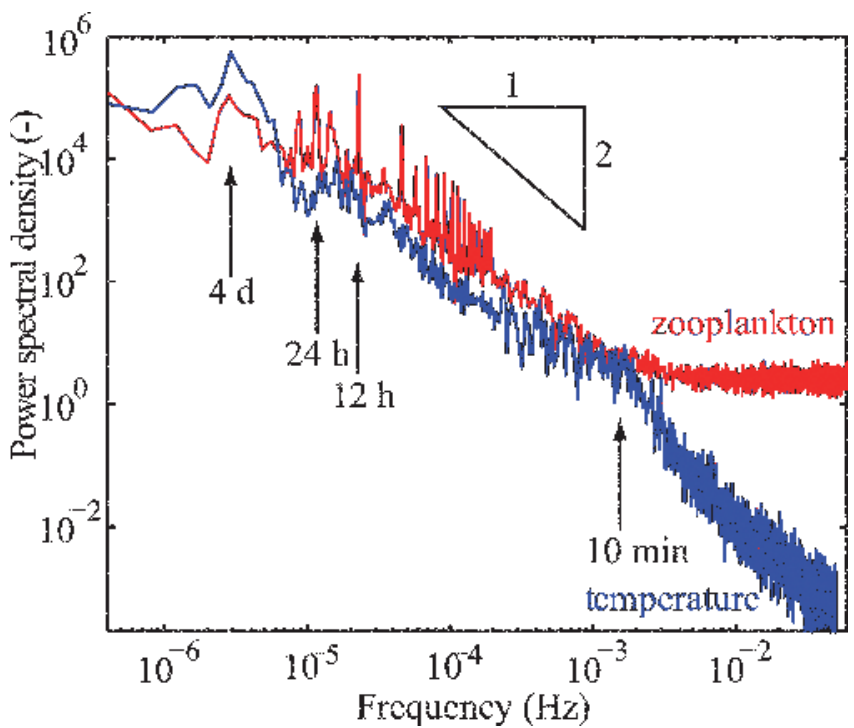

Fig. 7. Power spectra of acoustic abundance estimates (red) and temperature (blue) at 18-m depth. Both spectra are normalized by their integrals and represent composites, whereas the lowfrequency part $\left(f<2 \times 10^{-4} \mathrm{~Hz}\right)$ is estimated from data measured between 18 August and 03 November and averaged over 5 and $10 \mathrm{~min}$, respectively. The high-frequency part $\left(f>2 \times 10^{-4} \mathrm{~Hz}\right)$ is estimated from data measured between 06 and 13 October with respective resolutions of 3 and $10 \mathrm{~s}$. Periods associated with major spectral peaks discussed in the text are indicated. The hypotenuse of the triangle indicates a spectral slope of frequency to the power of -2 . Note that the narrow peaks in the abundance spectra are harmonics of the 24-h peak (i.e., at $12 \mathrm{~h}, 6 \mathrm{~h}, \ldots$ ) and are thus an artifact of the spectral analysis, resulting from the nonsinusoidal zooplankton variations associated with DVM.

were estimated over the entire deployment period of the high-resolution mooring of about $3.5 \mathrm{~d}$ (Fig. 8D). All spectra show a peak around the mean buoyancy frequency $N\left(N=[-g / \rho \times d \rho / d z]^{1 / 2} \sim 0.03 \mathrm{~s}^{-1}\right.$, where $\rho$ is density, $z$ is depth, and $g$ is gravitational acceleration), which marks the high-frequency limit for internal wave motions. At higher frequencies, where turbulent motions and diffusive transport dominate, the spectral variance of acoustic backscatter follows the decreases of variance in horizontal current velocities, whereas temperature and vertical velocity variances decrease more rapid with increasing velocities. At frequencies smaller than $N$ horizontal velocity, backscatter strength and temperature exhibit the same spectral slope $\left(\sim f^{-2}\right.$, with frequency $\left.f\right)$, and only the vertical velocity variance does not increase with decreasing frequencies.

\section{Discussion}

Scales of active and passive vertical motion of zooplankton-Based on the results of the comparison between acoustic backscatter strength with sampled zooplankton abundance, the acoustically observed patterns of DVM can be most probably related to migrating Daphnia. DVM of Daphnia in Lake Constance has been observed in a number of studies and has been described as a starvation avoidance (Geller 1986) and as a predator evasion (Stich and Lampert
1981) mechanism. Two different Daphnia species can be found in the lake, and whereas $D$. galeata remains within the epilimnion, $D$. hyalina is known to perform DVM from early summer until winter (Stich and Lampert 1981). Other zooplankton species in Lake Constance show no or less pronounced migrations (Geller 1986; Stich 1989).

The average migration depth of $D$. hyalina during summer was estimated by Geller (1986) to be $36 \mathrm{~m}$. Our observations suggest that the migration depth has increased since then. Possible explanations are increased light penetration as a result of reoligotrophication and/or drastically increased abundance of whitefish due to stocking (M. Peer and R. Eckmann pers. comm.). Our observations further reveal a relationship between the maximum migration depth and temperature during spring (Fig. 3B,C), when the depth of the $6^{\circ} \mathrm{C}$ isotherm seems to limit the amplitudes of DVM. The depth of this isotherm fluctuates on timescales between 3 and $4 \mathrm{~d}$ with amplitudes of up to $20 \mathrm{~m}$ caused by a basin-scale internal Kelvin wave (Appt et al. 2004; Lorke 2007). According to its long wavelength, this wave forms a shallow-water wave, and wave-induced current velocities are mainly restricted to the horizontal direction (Kundu and Cohen 2008). Vertical displacements are caused by the periodic in- and outflow of epilimnetic water and corresponding displacements of the thermocline. Figure 3C suggests that it is not the amplitude of DVM that is changing within a wave period, but the depth at which DVM starts. Greater isothermal depths are associated with a thicker mixed layer at the lake surface, where zooplankton are mixed by surface waves, windinduced turbulence, and nocturnal convection. Zooplankton starting from the deepest part of the surface mixed layer migrate the same vertical distance as zooplankton starting from near the surface, which explains the correlation between the maximum migration depth and the depth of a particular isotherm. Later in the year, DVM amplitudes are decoupled from the depth of the $6^{\circ} \mathrm{C}$ isotherm, and potential correlations to lower temperatures at greater depths could not be resolved by the limited profiling range of the ADP.

The daily timing of vertical migration closely followed the seasonal changes of solar radiation (Fig. 5A), confirming the predominantly laboratory observations that relative changes of light intensity $s r$ (Eq. 4) provide a stimulus for daily upward and downward migration (Ringelberg 1999). In contrast to former studies, the rheobase threshold for the beginning of secondary phototaxis was not only exceeded at dawn and dusk. Due to fluctuations in solar radiation caused by clouds as well as due to vertical displacement of zooplankton by internal waves, it was also frequently exceeded during the daytime. The relative change in light intensity perceived by the zooplankton organisms associated with vertical displacement due to internal waves depends on vertical velocity and on the light extinction coefficient only, and Eq. 4 can be rearranged to provide a critical condition for which the rheobase threshold $s r_{0}$ is exceeded:

$$
\left|\frac{d z}{d t} \cdot \varepsilon\right| \geq s r_{0}
$$



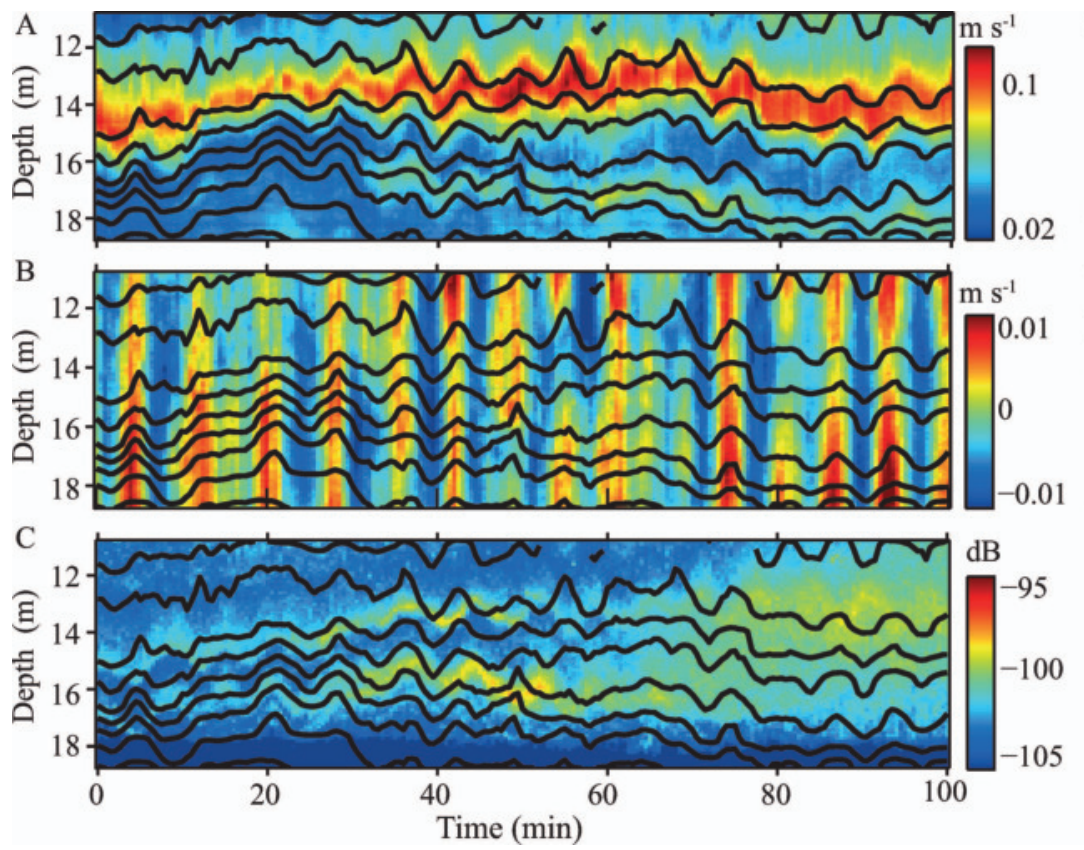

D

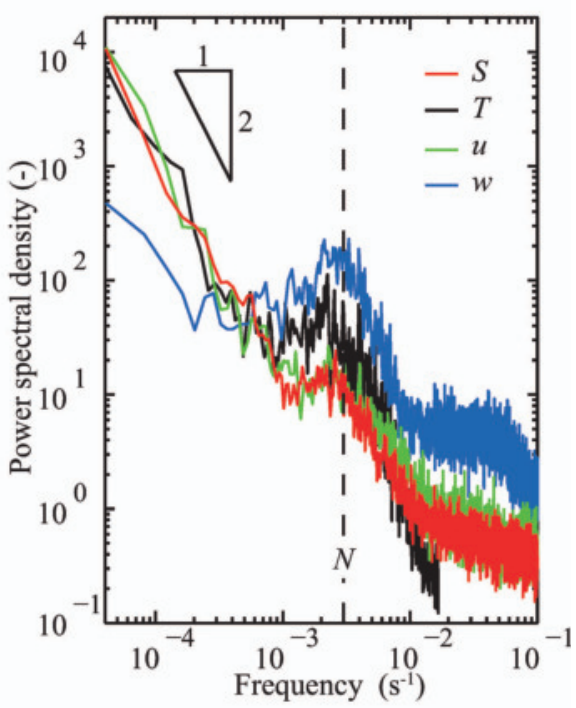

Fig. 8. High-resolution ADCP and temperature measurements in the thermocline: (A) Current speed, showing two metalimnetic jets moving in opposite directions, (B) vertical velocities associated with high-frequency internal wave motions, and (C) acoustic backscatter strength showing two thin layers of enhanced backscatter moving with the jets (note that acoustic backscatter in $\mathrm{dB}$ is related to the logarithm of particle or zooplankton concentration). Black lines show the depths of isotherms between $10^{\circ} \mathrm{C}$ and $14^{\circ} \mathrm{C}$ at $0.5^{\circ} \mathrm{C}$ increments and periodic displacements by internal waves. (D) Power spectra of acoustic backscatter strength $(S)$, temperature $(T)$, horizontal current velocity $(u)$, and vertical velocity $(w)$. The spectra are normalized by their integrals, and the triangle indicates a slope of frequency to the power of -2 .

where $d z / d t$ is the vertical velocity, and $\varepsilon$ is the light absorption coefficient, which was assumed to be independent of depth $z$. Depending on the sign of the vertical velocity, the phototaxic response of the organisms will be directed upward or downward. Using a rheobase threshold for $D$. galeata $\times$ hyalina of $s r_{0}=0.04 \mathrm{~min}^{-1}$ (Ringelberg 1999) and a typical absorption coefficient $\varepsilon=0.5 \mathrm{~m}^{-1}$, we find a critical vertical velocity of $1.3 \mathrm{~mm} \mathrm{~s}^{-1}$. Any vertical displacement with a velocity exceeding this value will result in a counteracting phototaxic response of Daphnia. It is interesting to note that this critical velocity is about equal to the observed vertical migration velocity (Fig. 5).

The phototaxic response of zooplankton, however, occurs not immediately, but only after some latent period, which depends on the relative change in light intensity. For values of this relative change caused by vertical velocities associated with the most energetic propagating internal waves of about $1 \mathrm{~cm} \mathrm{~s}^{-1}$ (Fig. 8), the latent period of Daphnia was estimated by van Gool and Ringelberg (1997) to be about $1 \mathrm{~min}$, indicating that vertical displacement by such waves can induce a continuously counteracting migration of Daphnia, which, however, cannot overcome the wave-induced vertical transport because of the slower migration velocity.

Spectral distribution of zooplankton variance-Spectral analysis of zooplankton abundance (Figs. 7, 8) in comparison to spectra of current velocity and passive tracers like temperature allows us to discriminate between passive transport and active migration of zooplankton. The observed spectra (Figs. 7, 8) indicate dominating passive vertical transport of zooplankton on a broad range of temporal scales. Long-term spectral estimates show close correspondences of spectral peaks around the period of the internal Kelvin wave ( $4 \mathrm{~d}$ ) and spectral slopes (i.e., the rate of decrease of spectral variance with increasing wave number). The major difference between the spectra of temperature and zooplankton abundance at low frequencies, i.e., at associated time periods exceeding $10 \mathrm{~min}$, is related to DVM. Similar to the spectra of spatial zooplankton distributions (Lovejoy et al. 2001; Currie and Roff 2006), the zooplankton spectra become flat and indistinguishable from white noise at higher frequencies in our long-term observations (Fig. 7). Based on theoretical arguments, Lovejoy et al. (2001) explain the transition to white noise or scale-independent randomness by the mobility of the zooplankton organisms with different swimming speeds, comparable to turbulent velocity fluctuations, occurring below some critical length scale, the plankton scale.

An alternative explanation for the deviation of temperature and zooplankton spectra at high frequencies is the wave-induced phototaxis analyzed previously, whereby the transition to white noise occurs at frequencies or associated length scales at which zooplankton migration can counteract and overcome passive vertical displacement. The frequency at which temperature and zooplankton spectra start to deviate is associated with a time period of about 
$10 \mathrm{~min}$ and coincides with the upper frequency limit for internal wave motion at the buoyancy frequency. The power spectra estimated from high-resolution measurements, however, suggest that the transition to white noise can also be an artifact of the limited vertical resolution of the long-term data. These measurements, which were performed with a spatial resolution of $10 \mathrm{~cm}$, in contrast to $1 \mathrm{~m}$, indicate that zooplankton variance decreases further with increasing frequencies, and with a spectral slope comparable to that of horizontal velocities (Fig. 8).

The combination of both the long-term and the highresolution spectra reveals the strong influence of internal wave motion on observed zooplankton variance at a broad range of scales. At high frequencies, zooplankton variance shows a local maximum at frequencies associated with a time period of about $10 \mathrm{~min}$, which coincides with the upper frequency limit for internal wave motion at the buoyancy frequency (Boegman et al. 2003; Lorke 2007). The strong and periodic vertical velocities associated with these waves result in identical vertical displacement of isotherms and zooplankton, which are passively transported (Fig. 8). At longer timescales, internal wave motion further shapes the spectral slopes of temperature and zooplankton. Both slopes are close to -2 ; this is observed in many lakes and can be related to the spectrum of random internal wave motion (Wüest and Lorke 2003). This spectral slope extends toward lower frequencies down to those associated with basin-scale motions. In these longwavelength waves, vertical velocities are negligible, and changes in the vertical distribution of both temperature and zooplankton are caused by horizontal transport. This effect is expressed in the identical spectral slope of temperature and zooplankton variance and the agreement of this slope with that of horizontal velocity fluctuations (Fig. 8D). The associated passive transport of zooplankton has also been described in earlier studies (Rinke et al. 2007, 2009) and eventually led to the observation of varying amplitude of DVM with the basin-scale internal Kelvin wave as shown in Fig. 3C and discussed herein.

The horizontal motion associated with basin-scale waves leads to synchronous transport of zooplankton and its food resources. Furthermore, the transport is oscillatory and therefore does not, on average, result in a net displacement of zooplankton. However, the combined effect of horizontal transport due to basin-scale internal waves and DVM may lead to a long-term net displacement of zooplankton and, more importantly, to a horizontal decoupling of zooplankton from their algal prey. The latter has an effect on the generation of horizontal patchiness, which depends on the period and phase relationship between DVM and internal wave motion.

\section{Acknowledgments}

We thank Beatrix Rosenberg, Joseph Halder, Florian Nonnenmann, and many students for their help during data collection and sample analysis. We acknowledge valuable comments and ideas provided by D. Straile, K. Rinke, and two anonymous reviewers. This study was financially supported by the German Research Foundation (Deutsche Forschungsgemeinschaft [DFG] grant Lo1150/2-2).

\section{References}

Aвraham, E. R. 1998. The generation of plankton patchiness by turbulent stirring. Nature 391: 577-580, doi:10.1038/35361

Antenucci, J. P., J. Imberger, And A. SAggio. 2000. Seasonal evolution of the basin-scale internal wave field in a large stratified lake. Limnol. Oceanogr. 45: 1621-1638, doi:10.4319/ 10.2000.45.7.1621

Appt, J., J. Imberger, AND H. Kobus. 2004. Basin-scale motion in stratified Upper Lake Constance. Limnol. Oceanogr. 49: 919-933, doi:10.4319/1o.2004.49.4.0919

Bäuerle, E., D. Ollinger, and J. Ilmberger. 1998. Some meterological, hydrological, and hydrodynamical aspects of Upper Lake Constance. Arch. Hydrobiol. Spec. Issues Advanc. Limnol. 53: 31-83.

Boegman, L., J. Imberger, G. N. Ivey, and J. P. Antenucci. 2003. High-frequency internal waves in large stratified lakes. Limnol. Oceanogr. 48: 895-919, doi:10.4319/lo.2003.48.2. 0895

Boehrer, B., J. Ilmberger, And K. O. Münnich. 2000. Vertical structure of currents in western Lake Constance. J. Geophys. Res. 105: 28823-28835, doi:10.1029/2000JC900139

Bracco, A., S. Clayton, and C. Pasquero. 2009. Horizontal advection, diffusion, and plankton spectra at the sea surface. J. Geophys. Res. 114: C02001, doi:10.1029/2007JC004671

Cohen, J. H., and R. B. Forward. 2009. Zooplankton diel vertical migration - a review of proximate control. Oceanogr. Mar. Biol. 47: 77-110, doi:10.1201/9781420094220.ch2

Cottier, F. R., G. R. Tarling, A. Wold, and S. Falk-Petersen. 2006. Unsynchronized and synchronized vertical migration of zooplankton in a high Arctic fjord. Limnol. Oceanogr. 51: 2586-2599, doi:10.4319/lo.2006.51.6.2586

Currie, W. J. S., AND J. C. RofF. 2006. Plankton are not passive tracers: Plankton in a turbulent environment. J. Geophys. Res. 111: C05S07, doi:10.1029/2005JC002967

Folt, C. L., AND C. W. Burns. 1999. Biological drivers of zooplankton patchiness. Trends Ecol. Evol. 14: 300-305, doi:10.1016/S0169-5347(99)01616-X

GelleR, W. 1986. Diurnal vertical migration of zooplankton in temperate great lake (L. Constance): A starvation avoidance mechanism? Arch. Hydrobiol. Suppl. 74: 1-60.

Greene, C. H., P. H. Wiebe, C. Pelkie, M. C. Benfield, and J. M. Popp. 1998. Three-dimensional acoustic visualization of zooplankton patchiness. Deep-Sea Res. II 45: 1201-1217, doi:10.1016/S0967-0645(98)00034-4

GÜDE, H., H. RossKnecht, AND G. WAGNER. 1998. Anthropogenic impacts on the trophic state of Lake Constance during the 20th century. Arch. Hydrobiol. Spec. Issues Advanc. Limnol. 53: $85-108$.

Hembre, L. K., and R. O. Megard. 2003. Seasonal and diel patchiness of a Daphnia population: An acoustic analysis. Limnol. Oceanogr. 48: 2221-2233, doi:10.4319/1o.2003.48.6. 2221

Holliday, D. V., P. L. Donaghay, C. F. Greenlaw, D. E. McGehee, M. M. McManus, J. M. Sullivan, and J. L. Miksis. 2003. Advances in defining fine- and micro-scale pattern in marine plankton. Aquat. Living Resour. 16: 131-136, doi:10.1016/S0990-7440(03)00023-8

Huntley, M. E., AND M. Zhou. 2004. Influence of animals on turbulence in the sea. Mar. Ecol. Prog. Ser. 273: 65-79, doi:10.3354/meps 273065

ImBERGER, J. 1998. Flux paths in a stratified lake: A review, p. 1-18. In J. Imberger [ed.], Physical processes in lakes and oceans. Coastal and estuarine studies. American Geophysical Union. 
Kundu, P. K., And I. M. Cohen. 2008. Fluid mechanics, 4th ed. Elsevier.

LORKe, A. 2007. Boundary mixing in the thermocline of a large lake. J. Geophys. Res. 112: C09019, doi:10.1029/ 2006JC004008

, D. F. McGinnis, P. SpaAk, and A. WÜest. 2004. Acoustic observations of zooplankton in lakes using a Doppler current profiler. Freshwater Biol. 49: 1280-1292, doi:10.1111/ j.1365-2427.2004.01267.x

-, F. Peeters, and E. Bäuerle. 2006. High-frequency internal waves in the littoral zone of a large lake. Limnol. Oceanogr. 51: 1935-1939, doi:10.4319/1o.2006.51.4.1935

, A. Weber, H. Hofmann, and F. Peeters. 2008. Opposing diel migration of fish and zooplankton in the littoral zone of a large lake. Hydrobiol. 600: 139-146, doi:10.1007/ s10750-007-9183-1

-, AND A. WÜEST. 2002. Probability density of displacement and overturning length scales under diverse stratification. J. Geophys. Res. 107: 1-11, doi:10.1029/2001JC001154

Lovejoy, S., W. J. S. Currie, Y. Tessier, M. R. Claereboudt, E. Bourget, J. C. Roff, and D. Schertzer. 2001. Universal multifractals and ocean patchiness: Phytoplankton, physical fields and coastal heterogeneity. J. Plankton Res. 23: 117-141, doi:10.1093/plankt/23.2.117

Mackas, D. L., K. L. Denman, and M. R. Aвbott. 1985. Plankton patchiness: Biology in the physical vernacular. Bull. Mar. Sci. 37: 652-674.

Martin, A. P., AND M. A. Srokosz. 2002. Plankton distribution spectra: Inter-size class variability and the relative slopes for phytoplankton and zooplankton. Geophys. Res. Lett. 29: 2213, doi:10.1029/2002GL015117

Pinel-Alloul, B., And A. Ghadouani. 2007. Spatial heterogeneity of planktonic microorganisms in aquatic systems: Multiscale patterns and processes, p. 203-307. In R. Franklin and A. Mills [eds.], The spatial distribution of microbes in the environment. Springer.

Pinot, J. M., AND J. JAnsá. 2001. Time variability of acoustic backscatter from zooplankton in the Ibiza Channel (western Mediterranean). Deep-Sea Res. I 48: 1651-1670, doi:10.1016/ S0967-0637(00)00095-9

Powell, T. M., AND A. OKubo. 1994. Turbulence, diffusion and patchiness in the sea. Phil. Trans. Roy. Soc. London B. 343: 11-18, doi:10.1098/rstb.1994.0002

Record, N. R., And B. De Young. 2006. Patterns of diel vertical migration of zooplankton in acoustic Doppler velocity and backscatter data on the Newfoundland Shelf. Can. J. Fish. Aquat. Sci. 63: 2708-2721, doi:10.1139/F06-157
Ringelberg, J. 1999. The photobehaviour of Daphnia spp. as a model to explain diel vertical migration in zooplankton. Biol. Rev. Cambridge Phil. Soc. 74: 397-423, doi:10.1017/ S0006323199005381

Rinke, K., A. Huber, S. Kempke, M. Eder, T. Wolf, W. N. Probst, AND K. O. RothHaupt. 2009. Lake-wide distributions of temperature, phytoplankton, zooplankton, and fish in the pelagic zone of a large lake. Limnol. Oceanogr. 54: 1306-1322, doi:10.4319/1o.2009.54.4.1306

, AND OTHERs. 2007. How internal waves influence the vertical distribution of zooplankton. Freshwater Biol. 52: 137-144, doi:10.1111/j.1365-2427.2006.01687.x

Schwoerbel, J. 1966. Methoden der Hydrobiologie Süßwasserbiologie, 3rd ed. Gustav Fischer Verlag. [Methods of Hydrobiology.]

Stich, H. B. 1989. Seasonal changes of diel vertical migrations of crustacean plankton in Lake Constance. Arch. Hydrobiol. Suppl. 83: 355-406.

-, and W. Lampert. 1981. Predator evasion as an explanation of diurnal vertical migration by zooplankton. Nature 293: 396-398, doi:10.1038/293396a0

- M. Pfeiffer, and G. Maier. 2005. Zooplankton communities in a large prealpine lake, Lake Constance: Comparison between the Upper and the Lower Lake. J. Limnol. 64: 129-135.

Straile, D., and W. Geller. 1998. Crustacean zooplankton in Lake Constance from 1920 to 1995: Response to eutrophication and re-oligotrophication. Arch. Hydrobiol. Spec. Issues Advanc. Limnol. 53: 225-274.

Sutor, M. M., T. J. Cowles, W. T. Peterson, and J. Lamb. 2005. Comparison of acoustic and net sampling systems to determine patterns in zooplankton distribution. J. Geophys. Res. 110: C10S16, doi:10.1029/2004JC002681

van Gool, E., and J. Ringelberg. 1997. The effect of accelerations in light increase on the phototactic downward swimming of Daphnia and the relevance to diel vertical migration. J. Plankton Res. 19: 2041-2050, doi:10.1093/ plankt/19.12.2041

Wüest, A., AND A. Lorke. 2003. Small-scale hydrodynamics in lakes. Ann. Rev. Fluid Mech. 35: 373-412, doi:10.1146/ annurev.fluid.35.101101.161220 